\title{
Demographics of extra-articular calcaneal fractures: including a review of the literature on treatment and outcome
}

\author{
Tim Schepers $\cdot$ Abida Z. Ginai • \\ Esther M. M. Van Lieshout • Peter Patka
}

Received: 25 June 2007 / Published online: 19 December 2007

(C) The Author(s) 2007

\begin{abstract}
Introduction Extra-articular calcaneal fractures represent $25-40 \%$ of all calcaneal fractures and an even higher percentage of up to $60 \%$ is seen in children. A disproportionately small part of the literature on calcaneal fractures involves the extra-articular type. The aim of this study was to investigate the incidence of extra-articular calcaneal fractures in a Level 1 trauma centre, define the distribution of the various types of fractures and compare patient demographics between extra- and intra-articular calcaneal fractures. In addition the literature was reviewed for the most common types of extra-articular calcaneal fractures with regard to incidence, treatment and clinical outcome.

Methods The radiological records between 2003 and 2005 were reviewed for intra- and extra-articular calcaneal fractures. Patient gender-distribution and age were compared. A literature search was conducted for the treatment of extra-articular calcaneal fractures.

Results In this 3-year study period a total of 49 patients with 50 extra-articular calcaneal fractures and 91 patients with 101 intra-articular fractures were identified. The median age for the first group was 32.7 years, and for the second group 40.3 years; $P=0.04$. Male predominance was significantly less pronounced for extra-articular (63\%) compared with intra-articular fractures $(79 \% ; P=0.04)$.
\end{abstract}

T. Schepers $(\bowtie) \cdot$ E. M. M. Van Lieshout · P. Patka Department of Surgery-Traumatology, Erasmus MC, University Medical Centre, Room H-974,

P.O. Box 2040, 3000 CA Rotterdam, The Netherlands

e-mail: t.schepers@erasmusmc.nl

A. Z. Ginai

Department of Radiology, Erasmus MC,

University Medical Centre, Rotterdam, The Netherlands
Conclusion One-third of all calcaneal fractures are extra-articular. Significant differences exist between the intra- and extra-articular groups, in terms of lower age and male-female ratio. The literature study shows inconsistencies in treatment options, but most extra-articular fractures are well manageable conservatively.

Keywords Calcaneus · Fracture $\cdot$ Extra-articular .

Treatment $\cdot$ Outcome

\section{Introduction}

The proportion of calcaneal fractures without involvement of the posterior subtalar joint in adults is reported to be approximately $25 \%[4,12,26]$. In children this number is higher and ranges from 25 to $63 \%$, with increased percentages at lower age [14, 41, 67]. A disproportionately small part of the literature on calcaneal fractures involves the extra-articular type [17]. Controversy exists in the treatment of calcaneal fractures in general, but to a lesser extent in the extra-articular type compared with intra-articular calcaneal fractures [47].

Extra-articular fractures of the calcaneus are compression or avulsion type fractures. According to several classifications, i.e. by Böhler [8], Essex-Lopresti [26] and others $[66,67,73]$, they are historically divided into three different groups: anterior portion, tuberosity (posterior calcaneal) and sustentaculum tali fractures (Table 1, Fig. 1). Several decades later additional calcaneal avulsion fractures of the calcaneus were identified $[13,55,58]$.

The aim of the current study was to assess the incidence of different types of extra-articular calcaneal fractures in a Level-1 trauma centre, and comparing patients with an extra- or intra-articular fracture. In addition, a review of the 
Table 1 Classification of extra-articular calcaneal fractures according to different authors

\begin{tabular}{|c|c|c|c|c|c|c|}
\hline Anatomical site & Fracture type & Böhler & Essex-Lopresti & Warrick-Bremner & Rowe & Schmidt-Weiner \\
\hline \multirow[t]{7}{*}{ Tuberosity } & Avulsion "beak type" & $1 \mathrm{a} / \mathrm{c}^{\mathrm{a}}$ & + & + & $2 \mathrm{a}$ & $2 \mathrm{a}$ \\
\hline & Achilles insertion & $1 \mathrm{~b}$ & - & - & $2 b$ & $2 b$ \\
\hline & Vertical-shear & 4 & - & + & 3 & 3 \\
\hline & Medial process & 2 & + & - & $1 \mathrm{a}$ & $1 \mathrm{a}$ \\
\hline & Horizontal & - & + & - & - & - \\
\hline & Apophysis & - & - & - & - & $1 \mathrm{a}$ \\
\hline & Bone loss & - & - & - & - & 6 \\
\hline Sustentaculum tali & & 3 & + & + & $1 b$ & $1 b$ \\
\hline \multirow[t]{3}{*}{ Anterior } & Calcaneocuboid & - & + & + & - & - \\
\hline & Anterior process & - & + & - & $1 \mathrm{c}$ & $1 \mathrm{c}$ \\
\hline & Inferolateral & - & - & - & - & $1 \mathrm{~d}$ \\
\hline Various & Avulsion fractures & - & - & - & - & $1 \mathrm{e}$ \\
\hline
\end{tabular}

Different fracture types are numbered as stated in the original classification. If the original classification did not use numbers, the presence of a certain fracture type is presented as - (no) or + (yes)

a Undisplaced (1a) or displaced (1c) "Beak" fracture according to Böhler

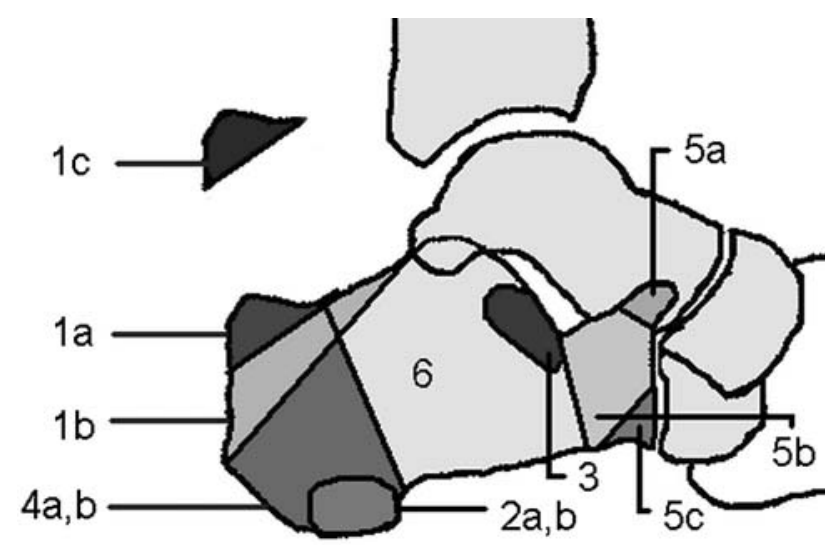

Fig. 1 Combined classification of extra-articular calcaneal fractures according to several authors (Table 1). 1 Undisplaced (1a) beak fracture; undisplaced $(1 b)$ avulsion fracture at Achilles-tendon insertion site; displaced (1c) "beak" avulsion fracture postero-superior aspect tuberosity; 2 medial $(2 a)$ or lateral $(2 b)$ process fracture; 3 isolated sustentaculum tali fracture; $4 a$ vertical fracture; $4 b$, apophysis avulsion fracture; $5 a$, anterior superior avulsion or compression fracture; $5 b$, calcaneocuboid joint fracture; $5 c$, distal inferolateral portion fracture; $6 a$, extensor digitorum avulsion fracture; $6 b$, plantar fascia avulsion fracture; $\sigma c$, posterior capsular avulsion fracture

literature was conducted concerning the incidence, treatment and outcome of common extra-articular calcaneal fractures.

\section{Patients and methods}

Patients

All radiological records between January 1, 2003 and December 31, 2005 were electronically reviewed for the combination "calcaneus" AND "fracture" (in Dutch) at a
Level 1 Trauma centre, with $\sim 24,000$ patients presenting at the ED annually. The starting point of this search coincided with the introduction of digital radiographs [Picture Archiving and Communication System PACS]. These records were reviewed manually and when a fracture of the calcaneus was suspected, the original radiographs were re-examined by two reviewers (TS, AG). Patient who had radiographs taken on more than one occasion, were included only once.

Fractures of the calcaneus were classified as extra- or intra-articular, with involvement of the posterior talocalcaneal joint in the latter. The extra-articular fractures were further divided into anterior calcaneal portion fractures (anterior process, calcaneocuboid joint fractures), sustentaculum tali fractures (mid calcaneal portion) posterior calcaneal portion fractures (tuberosity avulsion, vertical, lateral and medial process fractures) and a group consisting of various avulsion fractures.

\section{Statistical analysis}

Statistical analysis was performed using the Statistical Package for the Social Sciences (SPSS) version 12.0 (SPSS, Chicago, IL, USA). The median age between groups was compared with the non-parametric MannWhitney $U$ test. The difference in gender distribution and number of bilateral fractures between groups was analysed using the Chi-square test. Correlations were considered statistically significant with a $P$ value of $<0.05$.

\section{Literature search}

The literature was reviewed for the various types of extraarticular calcaneal fractures; their incidence, treatment and 
outcome. This search was conducted in the electronic databases of Embase, Cochrane Library and Pubmed using the following search-terms and Boolean operators: ("calcaneus" or "os calcis" or "calcaneum" OR "calcaneal") and "fracture(s)" and/or "avulsion" and/or "extra-articular" up to July 2007. In addition a hand search of reference lists of eligible manuscripts and review articles was conducted to identify additional studies.

\section{Results}

\section{Patients}

A total of 540 patients with the terms "calcaneus" AND "fracture" mentioned in their radiological records were retrieved in the three year study period. In 140 cases a fracture of the calcaneus was encountered and in an additional 97 patients a calcaneal fracture was sustained prior to the investigatory period; meaning these were control radiographs to assess healing or in cases with persisting physical complaints. These patients were excluded from further analysis.

Out of the 140 patients with a calcaneal fracture, 49 patients sustained 50 extra-articular fractures. The different types of extra-articular calcaneal fractures and their frequency of appearance are shown in Table 2. The most commonly encountered extra-articular calcaneal fractures were the anterior process $(n=19)$, the extensor digitorum brevis avulsion $(n=8)$ and tuberosity medial process fractures $(n=8)$.

Patients with an intra-articular fracture had a median age of 40.3 years, compared with those with an extra-articular

Table 2 Extra-articular calcaneal fractures $(n=50)$ seen between 2003 and 2005 in 49 patients

\begin{tabular}{lll}
\hline Fracture type & Numeric & Fractures $(n)$ \\
\hline Tuberosity avulsion & $1 \mathrm{a}$ & 1 \\
Medial tuberosity process & $2 \mathrm{a}$ & 8 \\
Lateral tuberosity process & $2 \mathrm{~b}$ & 1 \\
Sustentaculum tali fracture & 3 & 1 \\
Sustentaculum avulsion & 3 & 2 \\
Vertical tuberosity & $4 \mathrm{a}$ & 2 \\
Anterior superior process & $5 \mathrm{a}$ & 19 \\
Calcaneocuboid joint & $5 \mathrm{~b}$ & 1 \\
Distal inferolateral & $5 \mathrm{c}$ & 3 \\
Extensor digitorum brevis & $6 \mathrm{a}$ & 8 \\
Posterior capsular & $6 \mathrm{~b}$ & 1 \\
Plantar fascia & $6 \mathrm{c}$ & 3
\end{tabular}

Distribution of different extra-articular fracture types (see Fig. 1) and the number of times they were encountered fracture $32.7(P=0.04)$. The proportion of male patients was $79 \%$ in the first group, and in $63 \%$ the latter. This difference was statistically significant $(P=0.04)$. A total of ten patients with an intra-articular fracture sustained a bilateral fracture $(11 \%)$, in the extra-articular group one patient (2\%) sustained a bilateral fracture $(P=0.06)$.

\section{Literature review}

\section{Calcaneal tuberosity fractures}

Hippocrates already described tuberosity fractures of the calcaneus, resulting in gangrene and death if treated wrongly [25]. These fractures can be divided into avulsion ("beak" and Achilles avulsion) and shear-compression (vertical, lateral and medial process) fractures, although combinations have been described [68]. Tuberosity fractures, mainly shear-compression, comprise $12-40 \%$ of all calcaneal fractures encountered $[9,26,73]$.

Fractures of the tuberosity result mainly from a fall from height or striking the heel on a ledge (Fig. 2a, b) [9]. Medial process fractures are thought to be the first stage of complex fractures [68], but can occur as avulsion fractures of the medial plantar fascia insertion [26] or abductor hallucis muscle insertion at the medial process [58]. Lateral process fractures and trochlear process fractures are rare [53].

The avulsion fractures of the postero-superior portion of the tuberosity ("beak" fractures) are caused by contraction of the calf-muscles while landing on the forefoot [20, 70]. Instead of rupturing the Achilles-tendon a fragment of approximately $2-3 \mathrm{~cm}$ is avulsed of the calcaneus ("Boyer fracture") $[6,16,26,70]$. Fractures alike type 1a are probably caused by deeper fibres of the soleus muscle, tilting the fragment upwards or by a more proximal insertion of the Achilles-tendon, as the Achilles-tendon usually inserts at level 1b (Fig. 1) [48, 62]. These avulsion fractures are more common in elderly women, in which osteoporosis plays an important role [6, 24, 44, 48, 57, 62, 65, 68, 70]. Other trauma mechanisms for the avulsion fracture are isolated muscle contractions, as seen in an athlete starting a run, or by direct trauma to the heel [32].

Two additional distinct avulsion fracture types of the tuberosity exist, namely the neuropathic Charcot-like fractures in diabetics and avulsion fractures of the apophysis of the calcaneus $[2,6,35,43,50,52]$. The type 1 "Iowa fracture" according to Hedlund et al. [35] is an extra-articular tuberosity avulsion fracture near the insertion of the Achilles-tendon, occurring in patients with a history of diabetes.

The epiphysiolysis, a Salter-Harris type III fracture, occurs in children [2, 7, 40, 52]. It can be mistaken for Severs' disease (apophysitis by repeated stress) if the fracture is not displaced [7]. 
Fig. 2 Examples of several subtypes of extra-articular calcaneal fractures. a Medial process fracture, $\mathbf{b}$ vertical tuberosity fracture, $\mathbf{c}$ anterior process (Degan type I) fracture, d avulsion fracture at the insertion site of the extensor digitorum brevis muscle
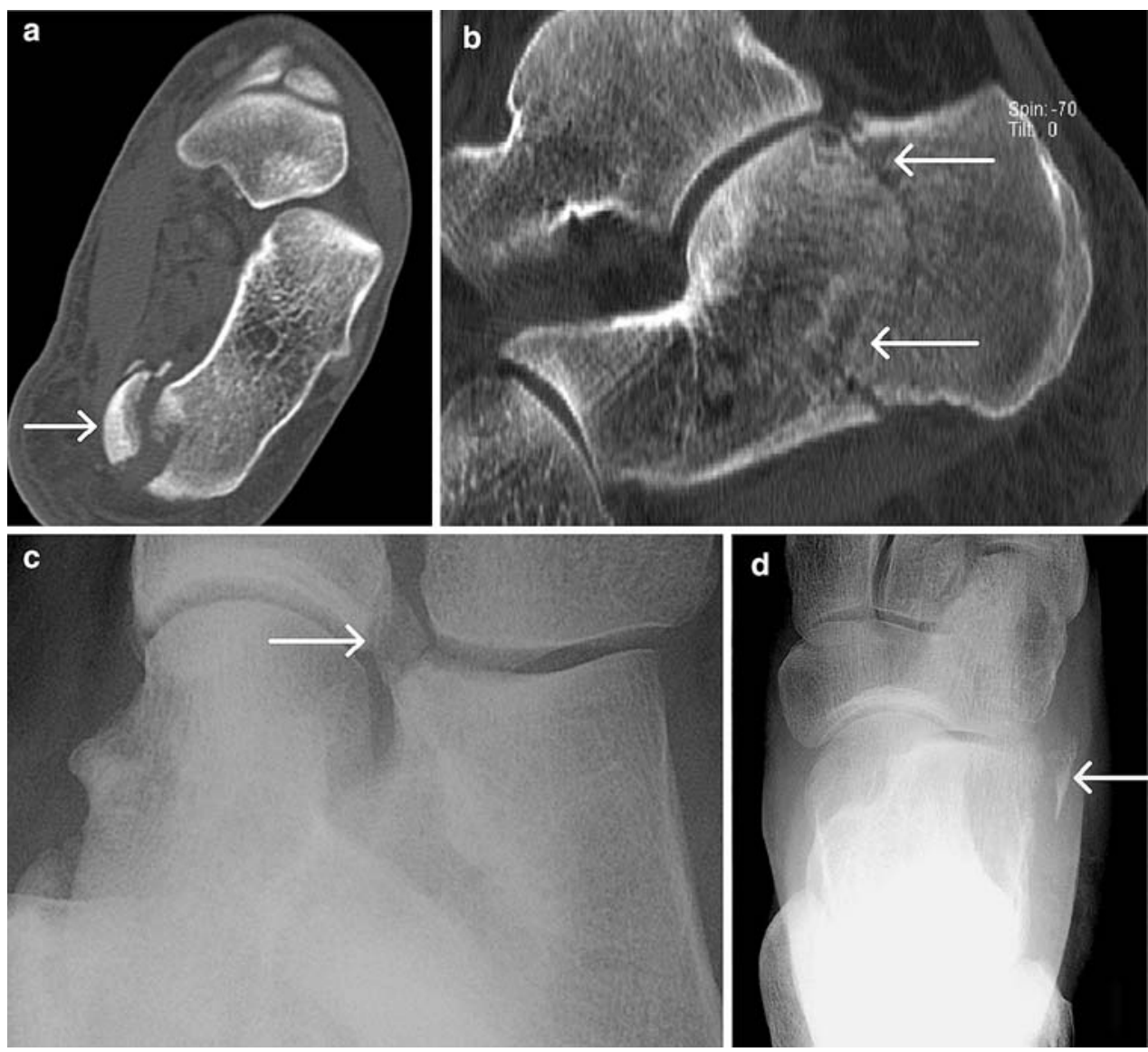

Tuberosity avulsion fractures treated inadequately lead to stiffness, pain en swelling at the insertion site of the Achilles-tendon. Residual complaints after conservative treatment are muscle weakness especially in plantar flexion, resulting in difficulty in climbing stairs or while walking on toes $[6,62]$. Most displaced tuberosity avulsion fractures are treated by open reduction and internal fixation (ORIF) with (tension-)wiring or screw fixation and an after-treatment in a above or below-knee cast for 4 or more weeks with the foot in plantar flexion (Table 3). Patients with low physical demands or fractures with minimally displaced fractures are manageable with conservative treatment $[62$, 65]. Medial process and minimally displaced vertical tuberosity fractures are managed conservatively with satisfactory outcome [53, 68].

\section{Sustentaculum tali fractures}

One of the earliest descriptions of sustentacular fractures was by Abel in 1878, who described three cases by direct force [25]. Isolated fractures of the sustentaculum tali are rare. Their incidence ranges from 0.3 to $4 \%[9,26,67,73]$.

According to Essex-Lopresti the sustentaculum tali fracture is an intra-articular one, whereas all other classifications group the sustentacular fractures as extra-articular
[26, 66, 67]. Treatment of isolated sustentaculum tali fractures is usually conservative with satisfactory results, as the sustentaculum tali remains in position by strong fixation to the talus by the deltoid ligament and the interosseous ligament $[8,15,17,31,37,72]$.

Anterior process fractures

The anterior process is a bony prominance situated at the anterior-superior front of the os calcis and goes by several names $[30,33]$. It is connected to both the cuboid and the navicular bone through the bifurcate ligamant [21]. Anterior process, or anterior-superior promontory, fractures (Fig. 2c) are overlooked or misdiagnosed as ankle-sprains in up to $40 \%$ of the cases in the Emergency Department [5, $21,27,28,30,42,46,71]$. Anterior process fractures represent $8-13 \%$ of all calcaneal fractures [26, 73]. Approximately $5 \%$ of patients with the history of an ankle-sprain has an anterior processus fracture, with a predominance in women [1, 10, 18, 27, 28, 54, 56].

Almost simultaneously Drachtler and Christopher reported this type of fracture for the first time in 1931 [18, 28, 64]. Different trauma mechanisms were postulated: forcible plantar-flexion (inversion-adduction, equinovarus, supination) of the foot $[5,10,18,21,28,30]$ and, less 
Table 3 Treatment and outcome of tuberosity avulsion fractures in the literature
LTF lost to follow-up, $N$ number

of patients treated, $N S$ not specified

${ }^{a}$ Avulsion fracture of the apophysis (epiphysiolysis) tuberosity of the calcaneus

${ }^{b}$ Neuropathic avulsion fractures of the tuberosity of the calcaneus

${ }^{c}$ Due to comorbidity

\begin{tabular}{|c|c|c|c|c|}
\hline \multirow[t]{2}{*}{ Author (year) } & \multicolumn{2}{|c|}{ Treatment } & \multicolumn{2}{|c|}{ Outcome } \\
\hline & $N$ & Description & $N$ & Description \\
\hline Partridge (1852) [57] & 1 & Plaster leg cast & 1 & Satisfactory \\
\hline Coote (1867) [20] & 1 & Iron splint & 1 & Satisfactory \\
\hline Thomson (1900) [70] & 1 & ORIF wiring & 1 & Satisfactory \\
\hline Eisendrath (1905) [24] & 2 & ORIF suturing & 2 & Satisfactory \\
\hline Cahill (1917) [16] & 1 & ORIF suturing & 1 & Satisfactory \\
\hline Mooney (1935) [52] & $1^{\mathrm{a}}$ & ORIF suturing & 1 & Satisfactory \\
\hline Rothberg (1939) [65] & 1 & ORIF suturing & 1 & Satisfactory \\
\hline Struppler (1939) [69] & 1 & Pin and plaster & 1 & Satisfactory \\
\hline Dieterle (1940) [22] & 1 & ORIF suturing & 1 & Satisfactory \\
\hline Arner (1959) [3] & 3 & ORIF & & NS \\
\hline \multirow[t]{2}{*}{ Protheroe (1969) [62] } & 2 & Conservative & 1 & Satisfactory \\
\hline & 3 & ORIF & 3 & Satisfactory \\
\hline \multirow[t]{2}{*}{ Lowy (1969) [48] } & 1 & Conservative & 0 & Satisfactory \\
\hline & 3 & ORIF & 3 & Satisfactory \\
\hline Lyngstadaas (1971) [49] & 2 & ORIF screws & & NS \\
\hline Alvarez F (1989) [2] & $1^{\mathrm{a}}$ & ORIF screws & 1 & Satisfactory \\
\hline Kathol (1991) [43] & $14^{\mathrm{b}}$ & NS & & NS \\
\hline \multirow[t]{2}{*}{ Biehl (1993) [6] } & $3^{b}$ & Conservative & 3 & Satisfactory \\
\hline & 1 & ORIF & 1 & Complicated \\
\hline Birtwistle (1995) [7] & $1^{\mathrm{a}}$ & ORIF screws & 1 & Satisfactory \\
\hline \multirow[t]{2}{*}{ Cole (1995) [19] } & 1 & Conservative & 1 & Satisfactory \\
\hline & 3 & ORIF & 3 & Satisfactory \\
\hline Levi (1997) [44] & 1 & ORIF wiring & 1 & Satisfactory \\
\hline Hedlund (1998) [35] & $12^{\mathrm{b}}$ & NS, 4/12 LTF & 7 & Satisfactory \\
\hline \multirow[t]{2}{*}{ Squires (2001) [68] } & 2 & Conservative & 0 & Satisfactory $^{c}$ \\
\hline & 1 & ORIF & 1 & Satisfactory \\
\hline Glanzmann (2005) [32] & 1 & ORIF (Mitek-Anchor) & 1 & Satisfactory \\
\hline Imai (2007) [40] & $1^{\mathrm{a}}$ & ORIF & 1 & Satisfactory \\
\hline \multirow[t]{3}{*}{ Overall } & 11 & Conservative & 7 & Satisfactory \\
\hline & 29 & ORIF & 23 & Satisfactory \\
\hline & 26 & NS & 31 & NS \\
\hline
\end{tabular}

common, dorsiflexion-eversion trauma or forcefull abduction of the forefoot with the heel fixed to the ground [21, 27, 61]. The first mechanism results in a avulsion fracture, the latter in a compression fracture [21]. Concomitant occurance of additonal injuries (talar, navicular, cuboid and calcaneal fracture or ligamental injuries) or calcaneo-navicular coalition are seen frequently [56, 59].

Clinical presentation includes: immediate pain at the dorsolateral side of the foot, losing the ability to bear weight after a few hours, swelling and later discoloration [10]. Tenderness is usually found by placing the thumb on the lateral malleolus and the third digit on the base of the fifth metatarsal, with the index finger pointing out the area of maximum pain ("Gellman grip") [28].

Radiographic investigation involves a lateral view of the calcaneus and a $45^{\circ}$ inverted oblique view or a $10^{\circ}-15^{\circ}$ cephalad, $10^{\circ}-15^{\circ}$ posterior view $[27,61]$. Other views are less sensitive [63]. If there is high suspectancy magnetic resonance imaging can be considered [56, 64]. The anterior process fracture must be distuinguised from a calcaneus secundarius, which can be found in $2-5 \%$ on autopsy [36, $38,39,51]$. Others consider the secondary ossicle to be a non-united anterior process fracture [64]. The fractures can be divided into three types according to Degan: Type I; an undisplaced fracture of only the tip of the anterior process, type II; displaced fracture of the anterior process not involving the calcaneocuboid joint, type III; large displaced fracture involving the calcaneocuboid joint [21]. Type I and II are sprain-fractures caused by inversion trauma, and type III is a compression fracture [61].

A successful treatment of anterior process fractures relies almost completely on the early detection of the fracture [10]. 
If not treated well this injury can cause persistent complaints for up to 18 months [46]. Conservative treatment, usually with a short leg cast for 4 weeks and increased weight-bearing, results in satisfactory outcome in most cases (Table 4) [10, 21, 36, 64]. In Degan type III fractures ORIF can be considered [39, 71]. The two most prognostic features of outcome are the type of injury and whether the fracture unites [21]. Overall outcome is satisfactory, but non-union rates range from zero to $40 \%$, depending on adequately made diagnosis and treatment [21, 28, 64]. "It is such injuries that very probably lead to the well-known expression that a bad sprain is worse than a fracture" [63].

\section{Anterior avulsion fractures}

The extensor digitorum brevis originates from the dorsolateral portion of the anterior portion of the calcaneus, and inserts at the lateral sides of the extensor digitorum longus tendons of the second to fourth toe, extending them with the foot in dorsal flexion.

If the foot is subjected to forceful inversion an avulsion fracture of the insertion of the extensor muscle may occur (Fig. 2d). Clinically it is difficult to distinguish between an anterior process (avulsion) fracture and an extensor digitorum brevis insertion avulsion fracture [34]. The haematoma, the point of maximum swelling and the point of maximum tenderness are situated in the same area as in anterior process fractures [55].

Norfray et al. [55] found 10 cases in a series of 100 consecutive patients suspected for an ankle fracture. The avulsion fracture was best seen at the dorsoplantar view of the foot and on the anteroposterior view of the ankle. An additional view recommended is the reversed oblique view of the foot, with the foot in approximately $35^{\circ}-40^{\circ}$ exorotation, e.g. supination $[13,29]$. Brijs identified 62 avulsions of the anterolateral aspect of the calcaneus, situated more peripherally
Table 4 Treatment and outcome of anterior process fractures in the literature
$L T F$ lost to follow-up, $N$ number of patients treated, $N S$ not specified, $N W B$ non-weight-bearing

\begin{tabular}{|c|c|c|c|c|}
\hline \multirow[t]{2}{*}{ Author (year) } & \multicolumn{2}{|c|}{ Treatment } & \multicolumn{2}{|c|}{ Outcome } \\
\hline & $N$ & Description & $N$ & Description \\
\hline Drachtler (1931) [23] & 26 & 4 weeks cast and NWB & 26 & Satisfactory \\
\hline \multirow[t]{2}{*}{ Christopher (1931) [18] } & 2 & Cast or taping & 2 & Satisfactory \\
\hline & 1 & No immobilisation & 0 & Satisfactory \\
\hline Gellman (1951) [28] & 6 & Short leg cast & 6 & Satisfactory \\
\hline \multirow[t]{2}{*}{ Bradford (1951) [10] } & 26 & Plaster 4-6 weeks & 25 & Satisfactory \\
\hline & & & 1 & Non-union \\
\hline Backman (1953) [5] & 20 & Tape or short leg cast & 20 & Satisfactory \\
\hline \multirow[t]{2}{*}{ Piatt (1956) [60] } & 10 & NS & 1 & Satisfactory \\
\hline & & & 2 & Non-union \\
\hline Garvin (1957) [27] & 12 & 8 weeks short leg cast & 12 & Satisfactory \\
\hline Levine (1959) [45] & 1 & None & 1 & Non-union \\
\hline Hellpap (1962) [36] & 47 & 4 weeks cast and NWB & 47 & NS \\
\hline \multirow[t]{2}{*}{ Carey (1965) [17] } & 47 & Short leg cast 5 weeks & 16 & NS \\
\hline & & & 30 & Satisfactory \\
\hline Hunt (1970) [39] & 1 & ORIF & 1 & Satisfactory \\
\hline Degan (1982) [21] & 25 & $\begin{array}{l}\text { Short leg cast } 5-6 \text { weeks } \\
7 \text { excisions ( } 5 \text { non-union) }\end{array}$ & 23 & Satisfactory \\
\hline \multirow[t]{2}{*}{ Renfrew (1985) [63] } & 7 & Cast or taping & 4 & NS \\
\hline & & & 3 & Satisfactory \\
\hline Trnka (1998) [71] & 1 & Excision of non-union & 1 & Satisfactory \\
\hline \multirow[t]{2}{*}{ Robbins (1999) [64] } & 3 & Immobilisation & 3 & Satisfactory \\
\hline & 2 & Delayed treatment & 2 & Non-union \\
\hline Hodge (1999) [38] & 1 & None & 1 & Non-union \\
\hline Pillai (2005) [61] & 1 & ORIF & 1 & Satisfactory \\
\hline Ouellette (2006) [56] & 14 & NS & 14 & NS \\
\hline Petrover (2007) [59] & 15 & NS & 15 & NS \\
\hline \multirow[t]{3}{*}{ Overall } & 224 & Conservative & 146 & Satisfactory \\
\hline & 2 & ORIF & 2 & Satisfactory \\
\hline & 42 & NS & 130 & NS \\
\hline
\end{tabular}


than fractures caused by avulsion of the extensor digitorum brevis. Brijs [13] suggested that these small fractures are caused by avulsions at the insertion site of the bifurcate ligament. Usually the avulsion is an isolated fracture and avulsed fragments resolved within a few months [11, 13, 29, 55]. Treatment is usually conservatively consisting of 2 weeks non-weight bearing, bandaging and early active motion exercises, and outcome is favourable in all patients [13, 29, 55].

\section{Discussion}

Thirty-five percent of all calcaneal fractures in the current study occurred outside the posterior subtalar joint. This percentage is slightly higher than previous incidences presented in the literature $[4,12,26]$. These percentages were calculated before the description of various types of avulsion fractures and might have been underscoring the number of extra-articular calcaneal fractures $[13,55]$.

Patients with an extra-articular calcaneal fractures were significantly younger, male predominance was less pronounced and the occurrence of a bilateral extra-articular calcaneal fractures is lower. This is explained largely by the difference in trauma-mechanism. The intra-articular calcaneal fractures occur frequently as work-related high-energy accidents and the extra-articular mainly as distortion injuries $[5,10,18,21,28,30,55]$.

A total of 66 tuberosity avulsion fractures were retrieved from the literature, including four epiphysiolyses. Patients treated conservatively reached a satisfactory result in $64 \%$ compared with $88 \%$ of patients treated operatively. Patients return to their daily activities earlier after operative treatment. No randomised trials exist on the subject and half of the patients were not available for follow-up. Nevertheless the tendency nowadays is to operate these avulsion fractures.

Some 268 cases with an anterior process fractures were identified, with $90 \%$ of the patients reaching satisfactory result after conservative treatment. As fragments are usually too small to fixate, operative treatment is not treatment of choice. Important in obtaining best outcome is an early detection of the injury and adequate immobilisation.

The 78 anterior avulsion fractures from the insertion of the extensor digitorum brevis muscle or bifurcate ligament described in the literature did well in $100 \%$ after conservative treatment, and only one large fragment was corrected operatively.

\section{Conclusion}

One-third of the calcaneal fractures are extra-articular. Statistically significant differences exist in patient characteristics, age and gender, between the intra- and extraarticular fractures. Evidence-based treatment options of extra-articular calcaneal fractures do not exist. Due to the low incidence of this type of fractures only retrospective case series and one prospective study regarding treatment options were found in the literature. Most extra-articular calcaneal fractures can be treated conservatively with overall satisfactory results. Displaced posterior superior avulsion fractures, displaced medial process and vertical fractures of the tuberosity and large anterior process fractures are best treated by ORIF according to the available literature.

Open Access This article is distributed under the terms of the Creative Commons Attribution Noncommercial License which permits any noncommercial use, distribution, and reproduction in any medium, provided the original author(s) and source are credited.

\section{References}

1. Agnholt J, Nielsen S, Christensen H (1988) Lesion of the ligamentum bifurcatum in ankle sprain. Arch Orthop Trauma Surg 107(5):326-328

2. Alvarez Fernandez JL, Villalba Vaquero M, Gomez Cimiano J (1989) Epiphysiolysis of the great tuberosity of the calcaneum: brief report. J Bone Joint Surg Br 71(2):321

3. Arner O, Lindholm A (1959) Avulsion fracture of the os calcaneus. Acta Chir Scand 117:258-260

4. Atkins RM, Allen PE, Livingstone JA (2001) Demographic features of intra-articular fractures of the calcaneum. Foot Ankle Surg 7:77-84

5. Backman S, Johnson SR (1953) Torsion of the foot causing fracture of the anterior calcaneal process. Acta Chir Scand 105(6):460-466

6. Biehl WC 3rd, Morgan JM, Wagner FW Jr, Gabriel R (1993) Neuropathic calcaneal tuberosity avulsion fractures. Clin Orthop Relat Res 296:8-13

7. Birtwistle SJ, Jacobs L (1995) An avulsion fracture of the calcaneal apophysis in a young gymnast. Injury 26(6):409-410

8. Böhler L (1931) Diagnosis, pathology and treatment of fractures of the os calcis. J Bone Joint Surg 1:75-89

9. Böhler L (1957) Die Technik der Knochenbruchbehandlung. Verlag Wilhelm Maudrich, Wien Band II, pp 2148-2217

10. Bradford CH, Larsen I (1951) Sprain-fractures of the anterior lip of the os calcis. N Engl J Med 244(26):970-972

11. Brandser E, Braksiek R, El-Khoury G, Saltzman C, Marsh J, Clark W, Prokuski L (1997) Missed fractures on emergency room radiographs: an analysis of 433 patients. Emerg Radiol 4(5):295-302

12. Bremner AE, Warrick CK (1951) Fractures of the calcaneus. J Fac Radiol 2(3):235-241

13. Brijs S, Brijs A (1992) Calcaneal avulsion: a frequent traumatic foot lesion. Rofo 156(5):495-496

14. Brunet JA (2000) Calcaneal fractures in children. Long-term results of treatment. J Bone Joint Surg Br 82(2):211-216

15. Burdeaux BD Jr (1993) The medial approach for calcaneal fractures. Clin Orthop Relat Res 290:96-107

16. Cahill GF (1917) Fractures of the os calcis. Ann Surg 66(6):711717

17. Carey DJ, Lance EM, Wade PA (1965) Extra-articular fractures of the os calcis-a follow-up study. J Trauma 8:362-372

18. Christopher F (1931) Fracture of the anterior process of the calcaneus. J Bone Joint Surg Am 1:877-879 
19. Cole RJ, Brown HP, Stein RE, Pearce RG (1995) Avulsion fracture of the tuberosity of the calcaneus in children. A report of four cases and review of the literature. J Bone Joint Surg Am 77(10): 1568-1571

20. Coote $\mathrm{H}$ (1867) Fracture of the os calcis from muscular action. Lancet 89(2270):270-271

21. Degan TJ, Morrey BF, Braun DP (1982) Surgical excision for anterior-process fractures of the calcaneus. J Bone Joint Surg Am 64(4):519-524

22. Dieterle J (1940) A case of so-called "open-beak" fracture of the os calcis. J Bone Joint Surg Am 2:740

23. Drachtler H (1931) Fractures of the anterior superior portion of the os calcis due to indirect violence. Am J Roentgenol 25(5):629-631

24. Eisendrath DN (1905) Fractures of the tarsal bones. Ann Surg 41(3):363-371

25. Ely LW (1906) Old fracture of the tarsus. Ann Surg 45(1):69-89

26. Essex-Lopresti P (1952) Mechanism, reduction technique and results in fractures of os calcis. Br J Surg 3:395-419

27. Garvin EJ, Rominger CJ (1957) Fractures of the anterior process of the calcaneus. Am J Surg 94(3):468-471

28. Gellman M (1951) Fractures of the anterior process of the calcaneus. J Bone Joint Surg Am 33-A(2):382-386

29. Geusens E, Geyskens W, Brys P, Janzing H (2000) The role of the reversed oblique radiograph in trauma of the foot and ankle. Eur Radiol 10(3):476-479

30. Gilheany M (2002) Injuries to the anterior process of the calcaneum. Foot 1:142-149

31. Gilmer PW, Herzenberg J, Frank JL, Silverman P, Martinez S, Goldner JL (1986) Computerized tomographic analysis of acute calcaneal fractures. Foot Ankle 6(4):184-193

32. Glanzmann M, Vereb L, Habegger R (2005) [Avulsion fracture of the calcaneal tuberosity in athletes]. Unfallchirurg 108(4):325-326

33. Golder WA (2004) Anterior process of the calcaneus: a clinicalradiological contribution to anatomical vocabulary. Surg Radiol Anat 26(3):163-166

34. Hall FM (1999) Calcaneal avulsion fractures. AJR Am J Roentgenol 173(3):854-855

35. Hedlund LJ, Maki DD, Griffiths HJ (1998) Calcaneal fractures in diabetic patients. J Diabetes Complications 12(2):81-87

36. Hellpap W (1962) Bone injuries of the anterior calcaneus process. Arch Orthop Unfallchir 5:329-338

37. Herzenberg JE (1986) CT of calcaneal fractures. AJR Am J Roentgenol 146(3):644-645

38. Hodge JC (1999) Anterior process fracture or calcaneus secundarius: a case report. J Emerg Med 17(2):305-309

39. Hunt DD (1970) Compression fracture of the anterior articular surface of the calcaneus. J Bone Joint Surg Am 52(8):1637-1642

40. Imai Y, Kitano T, Nakagawa K, Takaoka K (2007) Calcaneal apophyseal avulsion fracture. Arch Orthop Trauma Surg 127(5):331-333

41. Inokuchi $\mathrm{S}$, Usami $\mathrm{N}$, Hiraishi $\mathrm{E}$, Hashimoto T (1998) Calcaneal fractures in children. J Pediatr Orthop 18(4):469-474

42. Judd DB, Kim DH (2002) Foot fractures frequently misdiagnosed as ankle sprains. Am Fam Physician 66(5):785-794

43. Kathol MH, el-Khoury GY, Moore TE, Marsh JL (1991) Calcaneal insufficiency avulsion fractures in patients with diabetes mellitus. Radiology 180(3):725-729

44. Levi N, Garde L, Kofoed H (1997) Avulsion fracture of the calcaneus: report of a case using a new tension band technique. J Orthop Trauma 11(1):61-62

45. Levine J, Kenin A, Spinner M (1959) Nonunion of a fracture of the anterior superior process of the calcaneus; case report. J Bone Joint Surg Am 41-A(1):178-180

46. Lindsay WR, Dewar FP (1958) Fractures of the os calcis. Am J Surg 95(4):555-576
47. Lowery RB, Calhoun JH (1996) Fractures of the calcaneus. Part II: Treatment. Foot Ankle Int 17(6):360-366

48. Lowy M (1969) Avulsion fractures of the calcaneus. J Bone Joint Surg Br 51(3):494-497

49. Lyngstadaas $S$ (1971) Treatment of avulsion fractures of the tuber calcanei. Acta Chir Scand 137(6):579-581

50. Matsumura H, Jimbo Y, Kato T, Imai S (1998) Spontaneous calcaneal fracture after deep heel burns with diabetes. Burns 24(7): 683-686

51. Mercer J (1931) The secondary os calcis. J Anat 66(1):84-97

52. Mooney V (1935) Avulsion of the epiphysis of the os calcis. J Bone Joint Surg 17(4):1056-1057

53. Moore GE (1933) Fractures of the tuber calcanei involving the medial and lateral processes. Surg Gynecol Obstet 5:400-405

54. Nielsen S, Agnholt J, Christensen H (1987) Radiologic findings in lesions of the ligamentum bifurcatum of the midfoot. Skeletal Radiol 16(2):114-116

55. Norfray JF, Rogers LF, Adamo GP, Groves HC, Heiser WJ (1980) Common calcaneal avulsion fracture. AJR Am J Roentgenol 134(1):119-123

56. Ouellette H, Salamipour H, Thomas BJ, Kassarjian A, Torriani M (2006) Incidence and MR imaging features of fractures of the anterior process of calcaneus in a consecutive patient population with ankle and foot symptoms. Skeletol Radiol 35(11):833-837

57. Partridge (1852) Fracture of the os calcis. Lancet 60(1512):177

58. Pelletier JP, Kanat IO (1990) Avulsion fracture of the calcaneus at the origin of the abductor hallucis muscle. J Foot Surg 29(3):268 271

59. Petrover D, Schweitzer ME, Laredo JD (2007) Anterior process calcaneal fractures: a systematic evaluation of associated conditions. Skeletal Radiol 36(7):627-632

60. Piatt AD (1956) Fracture of the promontory of the calcaneus. Radiology 67(3):386-390

61. Pillai A, Arora J, Williams C, Ferdinand R (2005) The sprain fracture of the calcaneus revisited. Foot 1:198-201

62. Protheroe K (1969) Avulsion fractures of the calcaneus. J Bone Joint Surg Br 51(1):118-122

63. Renfrew DL, el-Khoury GY (1985) Anterior process fractures of the calcaneus. Skeletal Radiol 14(2):121-125

64. Robbins MI, Wilson MG, Sella EJ (1999) MR imaging of anterosuperior calcaneal process fractures. AJR Am J Roentgenol 172(2):475-479

65. Rothberg A (1939) Avulsion fracture of the os calcis. J Bone Joint Surg Am 2:218-220

66. Rowe C, Sakellarides H, Freeman P, Sorbie C (1963) Fractures of the os calcis. JAMA 184(12):98-101

67. Schmidt TL, Weiner DS (1982) Calcaneal fractures in children. An evaluation of the nature of the injury in 56 children. Clin Orthop Relat Res 171:150-155

68. Squires B, Allen PE, Livingstone J, Atkins RM (2001) Fractures of the tuberosity of the calcaneus. J Bone Joint Surg $\mathrm{Br}$ 83(1):55-61

69. Struppler V (1939) Avulsion fracture of the calcaneal tuberosity. Arch Orthop Trauma Surg 39(5):651-658

70. Thomson R (1900) A rare case of fracture of the os calcis by muscular force. Lancet 156(4025):133-134

71. Trnka HJ, Zettl R, Ritschl P (1998) Fracture of the anterior superior process of the calcaneus: an often misdiagnosed fracture. Arch Orthop Trauma Surg 117(4-5):300-302

72. Vollrath T, Eberle C, Grauer W (1987) Computed tomography of intra-articular calcaneal fractures. Rofo 146(4):400-403

73. Warrick CK, Bremner AE (1953) Fractures of the calcaneum, with an atlas illustrating the various types of fracture. J Bone Joint Surg $\mathrm{Br}$ 35-B(1):33-45 